\title{
Diel diving behavior of sperm whales off Japan
}

\author{
Kagari Aoki ${ }^{1, *}$, Masao Amano ${ }^{2}$, Motoi Yoshioka ${ }^{3}$, Kyoichi Mori ${ }^{4}$, Daisuke Tokuda ${ }^{3}$, \\ Nobuyuki Miyazaki ${ }^{1}$
}

\author{
${ }^{1}$ Ocean Research Institute, The University of Tokyo, 1-15-1 Minamidai, Nakano, Tokyo 164-8639, Japan \\ 2 Department of Animal Sciences, Teikyo University of Science \& Technology, 2525 Yatsusawa, Uenohara \\ Yamanashi 409-0193, Japan \\ ${ }^{3}$ Graduate School of Bioresources, Mie University, 1577 Kurimamachiya, Tsu, Mie 514-8507, Japan \\ ${ }^{4}$ Ogasawara Whale Watching Association, Aza Higashi, Chichijima, Ogasawara, Tokyo 100-2101, Japan
}

\begin{abstract}
Diel changes in the diving behavior of cetaceans have been documented only in some shallow divers, such as smaller toothed whales and some baleen whales. In this study, we attached data loggers to sperm whales Physeter macrocephalus, one of the deepest and longest divers among all marine mammals, to investigate the possible diel patterns in the species. We conducted the experiments in 2 areas off Japan (the Kumano Coast and the Ogasawara Islands). Obvious diel patterns of diving behavior were found off the Ogasawara Islands, where the whales dived deeper and swam faster during the day than at night (day-time depth: mean $853 \pm 130$ (SD) $\mathrm{m}, n=35$; night-time depth: mean $469 \pm 122 \mathrm{~m}, n=31$; day-time velocity: mean $2.0 \pm 0.3 \mathrm{~m} \mathrm{~s}^{-1}, n=20$; night-time velocity: mean $1.5 \pm 0.3 \mathrm{~m} \mathrm{~s}^{-1}, n=19$ ). On the other hand, off the Kumano Coast, whales showed no diel rhythm in diving depths or swimming speed (day-time depth: mean $646 \pm 212 \mathrm{~m}, n=83$; night-time depth: mean $561 \pm 229 \mathrm{~m}, n=44$ and day-time velocity: mean $1.9 \pm 0.5 \mathrm{~m} \mathrm{~s}^{-1}, n=57$; night-time velocity: mean 1.6 $\pm 0.5 \mathrm{~m} \mathrm{~s}^{-1}, n=33$ ). We suggest that the environmental differences between these 2 areas contributed to the difference in diel behavior of the whales, which was mediated by the diel behavior of their prey.
\end{abstract}

KEY WORDS: Sperm whales $\cdot$ Cetacean $\cdot$ Diving behavior $\cdot$ Diel patterns $\cdot$ Foraging $\cdot$ Thermocline Resale or republication not permitted without written consent of the publisher

\section{INTRODUCTION}

Diel patterns in behavior have been documented in many marine mammals. For some whales, diel patterns are generally related to the timing of feeding, and hence should be appropriately coordinated with environmental conditions, such as food availability. For example, common dolphins Delphinus delphis in the northeastern Pacific stayed near the sea surface during the day, at which time their prey remained in deep waters (200 to $300 \mathrm{~m}$ ), and dived to the depth of the deep scattering layer at night to feed on prey that are available (40 to $50 \mathrm{~m}$, Leatherwood \& Evans 1979). Similar behavior was reported in fin whales Balaenoptera physalus in the Ligurian Sea (Panigada et al. 1999). These animals are thought to predict the temporal and spatial distribution of their prey (Panigada et al.
1999). Nocturnal feeding requires a lower commuting cost than diurnal feeding for dolphins and whales because their prey stays in relatively shallow water at night (Kooyman et al. 1992); hence, it is thought that dolphins and baleen whales prefer to feed at night.

Although it has been shown that the diel foraging behavior of shallow-diving cetaceans depends on the behavior of their prey, little is known about the effects of diel behavior of prey on the foraging behavior of deep-diving cetaceans. Sperm whales Physeter macrocephalus are one of the deepest and longest divers among marine mammals. The whales routinely dive to depths $>400 \mathrm{~m}$, which have been interpreted as foraging dives. In addition, the whales spend almost the entire day in these foraging dives (Watkins et al. 2002, Amano \& Yoshioka 2003, Watwood et al. 2006). Diel behavior of sperm whales may be different from that of 
other smaller toothed whales and baleen whales because their diving capacity is greater and the duration of feeding bouts is longer.

Sperm whales feed mainly on mesopelagic and bathypelagic squid, such as squid from the families Gonatid, Histioteuthid and Onychoteuthid (Kawakami 1980). Some of these squids, such as several species of Gonatus, conduct diel vertical migrations (Roper \& Young 1975), which may affect the foraging behavior of sperm whales. Matsushita (1955) proposed that the sperm whales in the Antarctic feed mainly at night when the squids rise to the sea surface because it was observed that the stomach contents of whales early in the morning and at night was greater than that of those caught during the day. On the other hand, more recent studies using radio tags, acoustic tracking or satellitelinked dive recorders, found no obvious diel variation in the diving depth of sperm whales (Papastavrou et al. 1989, Watkins et al. 2002, Davis et al. 2007).

In this study, we investigated diving behavior of sperm whales using data loggers in 2 areas (the Kumano Coast and the Ogasawara Islands) off Japan. We found obvious diel patterns of diving behavior off the Ogasawara Islands. Here we focus on differences in diel diving behavior between these 2 areas and suggest possible factors affecting diel diving behavior in sperm whales.

\section{MATERIALS AND METHODS}

Tag components. We used 2 types of data loggers: the Mk6 model $(75 \mathrm{~mm}$ in length, $55 \mathrm{~mm}$ in width, $30 \mathrm{~mm}$ in height, $90 \mathrm{~g}$ in the air; Wildlife Computers) and the UWE2000-PDT model (21 $\mathrm{mm}$ in diameter, $123 \mathrm{~mm}$ in length, $64 \mathrm{~g}$ in the air; Little Leonardo). We used the MK6 from 2000 to 2004 and the UWE2000PDT from 2002 to 2004. The loggers recorded depth at $1 \mathrm{~s}$ intervals and velocity at $3 \mathrm{~s}$ intervals in 2000 and at $1 \mathrm{~s}$ intervals from 2001 to 2004. Water temperature was also recorded at 3 s intervals in 2000 and 2001, and at $1 \mathrm{~s}$ intervals from 2002 to 2004. The measurement range of the depth sensor of both loggers was $0-2000 \mathrm{~m}$. The resolution of the depth sensor of the Mk6 was $8 \mathrm{~m}$ and that of the UWE-2000-PDT was $0.5 \mathrm{~m}$. The resolutions of the temperature sensor of the Mk6 and the UWE-2000-PDT were $0.1^{\circ} \mathrm{C}$ and $0.01^{\circ} \mathrm{C}$, respectively. Velocity was measured using the rotation of a propeller on both loggers.

We attached data loggers to sperm whales using 2 types of suction-cup-attached tags. The type A tag was similar to that used in several other studies (Baird et al. 2001, 2002, Amano \& Yoshioka 2003). All off the tags were made by the authors. The type A tag body was composed of a logger, a float made of synthetic foam and a VHF radio transmitter (Advanced Telemetry Systems). An $8 \mathrm{~cm}$ diameter suction cup (Canadian Tire) was attached to the tag body with a plastic tube (Type A tag). Velocity could not be measured accurately with the Type A tag in combination with the UWE2000-PDT. The problem was due to the differences between the Mk6 and the UWE-2000-PDT in the plane of the propeller rotation and body shape. In the situation of the MK6, the plane of the propeller rotation is parallel with the longest axis of the logger, and the apertural area of the water stream is wider than that of the UWE-2000-PDT. Therefore, the rotation of the propeller does not depend on the direction of the logger. In the case of the UWE-2000-PDT, however, the plane of the propeller rotation is orthogonal with the longest axis of the logger (i.e. the propeller rotates around the longest axis of the logger), and the side of the propeller is surrounded by a metal frame. Therefore, the propeller can rotate only when the water stream comes straight over it; in other words, the rotation of the propeller is dependent on the direction of the logger against the water stream. We modified the Type A tag by adding a vertical tail fin to the UWE-2000-PDT, which was attached to a suction cup, so that the logger would always align with the water stream. In this way, its propeller always faced the swimming direction of the whale (Type B tag). The tags weighed 410 to $450 \mathrm{~g}$.

Field studies. Field studies were conducted off the Kumano Coast (on Japan's southern Pacific Coast) and off the Ogasawara Islands (also known as the Bonin Islands, a subtrobical archipelago located ca. $1000 \mathrm{~km}$ directly south of central Tokyo in the western Pacific Ocean) from 2000 to 2004 (Fig. 1). Off the Kumano Coast is the Kuroshio Current, one of the strongest currents in the world. Groups of sperm whales migrate into the region in late spring to summer (May to September) and are frequently observed on the northern margin of the Kuroshio Current (Takahashi 2001). Off the Ogasawara Islands there is no remarkable ocean current, and a thick isothermal layer, called the North Pacific Subtropical Mode Water (NPSTMW), sits at 150 to $400 \mathrm{~m}$ depth almost all year (Taneda et al. 2000). Groups of sperm whales are observed in water with maximum bottom depths greater than $1000 \mathrm{~m}$ throughout the year (Mori et al. 1995).

We approached sperm whales by boat (length: 14 to $16 \mathrm{~m}$ ) at slow speeds and deployed the tags using a crossbow or a $6 \mathrm{~m}$ pole. After tag deployment, we followed the whale to observe its behavior, while trying to avoid any kind of disturbance. Once the tag was detached from the whale, it was retrieved from the sea surface by tracking the VHF signals.

We determined the whales' sex using the zinc-finger gene DNA extracted from a skin sample retrieved from the suction cup. When the genetic data were not avail- 


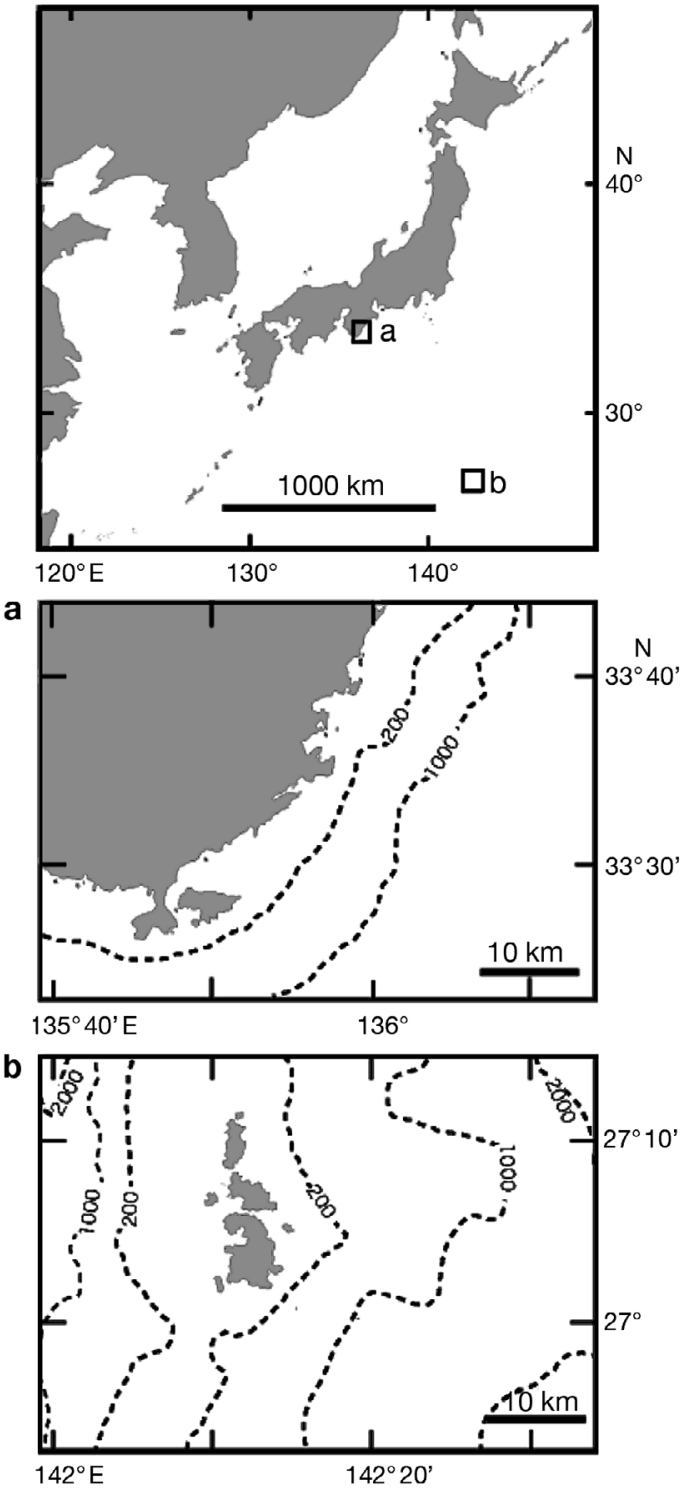

Fig. 1. (a) Kumano Coast and (b) Ogasawara Islands. Detail maps show isobaths $(\mathrm{m})$

able, we determined sex on the basis of callus formation on the dorsal fin, which is a characteristic of mature females (Kasuya \& Ohsumi 1966).

Data analysis. All deep dives (>200 m) were divided into 3 phases: (1) descent phase (time between the beginning of a dive and the beginning of horizontal movement, defined as the time of first ascent or the beginning of the first time at which the vertical depth change rate was zero for at least $10 \mathrm{~s}$ ); (2) ascent phase (time between the end of horizontal movement, defined as the time of last descent or the end of the last time at which the vertical depth change rate was zero for at least $10 \mathrm{~s}$, and the end of the dive); and (3) bottom phase (the time between the end of the descent phase and the beginning of the ascent phase). Wiggles during the bottom phase were defined as the number of points (i.e. a vertical depth change rate of at least $20 \mathrm{~m}$ ) before the next inflection.

We calibrated the velocity data based on the methods of Blackwell et al. (1999) and Amano \& Yoshioka (2003). Velocity was calculated from the number of rotations of the data logger's propeller according to a linear relationship directly proportional to the vertical depth change rate. Due to the resolution of the depth sensor, we calculated the average velocity and the vertical depth change rate at 1 min intervals in the Mk6 and at $10 \mathrm{~s}$ intervals in the UWE-2000-PDT. For each whale, we regressed 3, 5, 10, 15 and 20 percentile points of velocity data to corresponding vertical depth change rates, and used the line with the highest regression coefficient value. The R-values were relatively high, ranging from 0.947 (Whale O4) to 0.998 (Whale W5a), excluding whales O2, O3 and W4b. Velocity data obtained by Type A tag when used with the UWE2000-PDT was not measured correctly, possibly due to the tag design, which caused the propeller of the logger to occasionally miss the water stream. Thus, we omitted the velocity data from this type of combination (data from whales $\mathrm{O} 2$ and O3) from further analyses. As the highest R-value for Whale W4b was relatively low (0.8771), we did not calibrate the velocity data for this whale and presented the measurement as the number of propeller rotations per second (Appendix 2).

The time constant of the temperature sensor is approximately $7.8 \mathrm{~s}$ for the UWE-2000-PDT and approximately $120 \mathrm{~s}$ for the Mk6. The vertical depth change rate must be $<0.13 \mathrm{~m} \mathrm{~s}^{-1}$ for the UWE-2000PDT and $<0.008 \mathrm{~m} \mathrm{~s}^{-1}$ for the Mk6 in order to measure water temperature accurately at $1 \mathrm{~m}$ intervals. In this respect, the whales' descent and ascent rates were too high ( 0.3 to $2.2 \mathrm{~m} \mathrm{~s}^{-1}$ ). To minimize the effect of the response function of the temperature sensor on temperature profiles, we conducted the following detailed analysis of water temperature obtained using the UWE-2000-PDT model. We calculated the average vertical depth change rates at $5 \mathrm{~s}$ intervals and measured water temperature at average vertical depth change rates of $<1.1 \mathrm{~m} \mathrm{~s}^{-1}$ for each whale. Next, we calculated vertical temperature profiles by averaging temperatures recorded during the descent and ascent phases (Charrassin et al. 2004). We defined a thermal gradient, the change in water temperature between a given depth and a depth $10 \mathrm{~m}$ deeper, to examine differences in vertical water temperature profiles between the 2 areas studied. The thermal gradient, which indicates the relative strength of the thermocline, was calculated for each $10 \mathrm{~m}$ depth. For example, the thermal gradient at $10 \mathrm{~m}$ was calculated as the 
water temperature at $10 \mathrm{~m}$ minus that at $20 \mathrm{~m}$. We computed the thermal gradient for each whale's data.

To examine whether methods of correcting temperature data obtained with the UWE-2000-PDT described above are suitable, we simultaneously measured water temperature at $1 \mathrm{~s}$ intervals using a COMPACT-TD (44 $\mathrm{mm}$ in diameter, $244 \mathrm{~mm}$ in length, $700 \mathrm{~g}$ in the air, $0.001^{\circ} \mathrm{C}$ in resolution, time constant $=$ ca. $0.2 \mathrm{~s}$; Alec Electronics) and the UWE-2000-PDT both off the Kumano Coast and off the Ogasawara Islands in the seasons of our field study in 2006. After that, we performed the above-mentioned methods for water temperature obtained with the UWE-2000-PDT. A Comparison of water temperatures obtained by the COMPACT-TD and the UWE-2000-PDT showed no significant differences (Mann-Whitney $U$-test: off Kumano Coast, $\mathrm{p}=0.7121$; off Ogasawara Islands, $\mathrm{p}=$ 0.7329).

The dives were separated into day and night groups on the basis of the local times of sunrise and sunset. For the statistical tests, all diving data were log-transformed to approximate normality and homogeneity of variance. Dive parameters (e.g. mean dive depth, dive duration) were compared between day and night in each area using a 2-factor ANOVA with repeated measures (Zar 1996). In this mixed model design, each dive record was assigned to either a 'day' or 'night' condition. The model specified 'day/night' as the fixed factor and 'whale' as the random factor. Differences in dive parameters between day and night were assessed with the F-ratio. The F-ratio was the mean-square 'day/night' divided by the mean-square interaction of 'day/night' with 'whale'. The statistical comparisons were 2-tailed (Zar 1996). We calculated the meansquare of each factor using JMP (SAS Institute).

Nonparametric statistical analysis was performed for water temperature using Stat View (SAS Institute). Values for statistical significance were set at $\mathrm{p}<0.05$. We report means $\pm \mathrm{SD}$.

\section{RESULTS}

\section{Tag attachment}

We attached tags to 10 sperm whales: 4 off the Kumano Coast and 6 off the Ogasawara Islands. A total of $182 \mathrm{~h}$ of data, including 193 dives, was obtained. All tagged whales were mature females or immature males and females (Table 1).

Reactions of the whales to the tag deployment were not intense, ranging from no apparent response to a brief startle, spy hops, or tail slaps. Similar behavior was reported by Miller et al. (2004a). The behavior of the tagged whales was not different from that of the other whales in the group, and no active avoidance of the research boat was observed. Dive profiles did not show apparent negative effects in response to the tagging; an exception was noted for Whale W0, whose first 2 dives were shorter (18.1 and $11.3 \mathrm{~min}$ ) and shallower (488 and $384 \mathrm{~m}$ ) than the following dives, and the surface time after these dives was relatively short (5 min). We suspect that these 2 early dives may have been influenced by the tag deployment, and so we removed them from further analyses. Detailed diving behavior of Whale W0 is shown in Amano \& Yoshioka (2003).

\section{Differences in diving behavior between the Kumano Coast and Ogasawara Islands}

The tagged sperm whales spent most of their time in deep dives that exceeded a depth of $200 \mathrm{~m}$ (73.6 \pm $19.6 \%, \mathrm{n}=10$ ) (Fig. 2). Almost all of these deep dives had a distinct bottom phase during which the depth varied widely (Amano \& Yoshioka 2003, their Fig. 2). Furthermore, some bursts in velocity were observed during the bottom phases (Amano \& Yoshioka 2003, their Fig. 2). The tagged sperm whales stayed near the

Table 1. Physeter macrocephalus. Summary of tags deployed on sperm whales. Sex was determined using genetic analysis of skin recovered with tag or the callus formed on the dorsal fin (the latter indicated as $\mathrm{F}^{\mathrm{a}}$ ). See 'Materials and Methods' for tag type

\begin{tabular}{|lccccccc|}
\hline Whale ID & Sex & $\begin{array}{c}\text { Estimated body } \\
\text { length }(\mathrm{m})\end{array}$ & Location & $\begin{array}{c}\text { Deployment } \\
\text { date }\end{array}$ & $\begin{array}{c}\text { Duration of } \\
\text { attachment (h) }\end{array}$ & Tag type & Data loggers \\
\hline W0 & F & $10-11$ & Kumano & $20 / 06 / 2000$ & 62.0 & A & Mk6 \\
O1a & M & $7-8$ & Ogasawara & $14 / 10 / 2001$ & 13.5 & A & Mk6 \\
O1b & F & $8-9$ & Ogasawara & $16 / 10 / 2001$ & 16.8 & Mk6 \\
O1c & F & $8-9$ & Ogasawara & $17 / 10 / 2001$ & 12.5 & Mk6 \\
O2 & F & $10-11$ & Ogasawara & $19 / 10 / 2002$ & 9.3 & A & UWE-2000PDT \\
O3 & $F^{\text {a }}$ & $10-11$ & Ogasawara & $15 / 10 / 2003$ & 13.4 & UWE-2000PDT \\
W4a & $F^{\text {a }}$ & $8-9$ & Kumano & $25 / 05 / 2004$ & 15.9 & A & Mk6 \\
W4b & $F^{\text {a }}$ & $9-10$ & Kumano & $28 / 05 / 2004$ & 31.3 & M & UWE-2000PDT \\
W4c & - & $7-8$ & Kumano & $28 / 05 / 2004$ & 5.0 & B & UWE-2000PDT \\
O4 & - & $7-8$ & Ogasawara & $23 / 10 / 2004$ & 2.8 & & B \\
\hline
\end{tabular}


surface for a few hours $(2.9 \pm 2.0 \mathrm{~h}, \mathrm{n}=9)$ at least once a day, except for Whale O4, possibly due to shorter tag duration (Fig. 2). The mean maximum dive depth and dive duration were $716.4 \pm 83.9 \mathrm{~m}$ and $35.1 \pm 3.0 \mathrm{~min}$ ( $\mathrm{n}=10$ ), respectively. The deepest dive recorded was $1304 \mathrm{~m}$, and the longest dive duration was $49.6 \mathrm{~min}$.

Off the Ogasawara Islands, tagged sperm whales dived to 800-1000 $\mathrm{m}$ during the day, but the dive depth decreased just after sunset, and the whales dived to 400-600 m at night. Whale O1b was an exception, in which 3 deep dives after sunset were followed with shallow dives to 400-600 m. We observed long surface times, during which the whales remained near the sea surface and did not make deep dives at night (Figs. 2a \& 3a, Appendix 1). On the other hand, off the Kumano Coast, Whale W0 dived almost all day to a wider range of depths (400-1200 m) than the whales off the Ogasawara Islands. Other whales tagged in 2004 dived to the shallower depths of 400-800 m during both the day and night. Long surface times were observed during the afternoon and evening for Whale W0 and at various times for other whales (Figs. 2b \& 3b, Appendix 2).

Because diel diving behavior of whales showed differences between the 2 areas, we examined whether diel diving depth of the whales was different between these

(a)
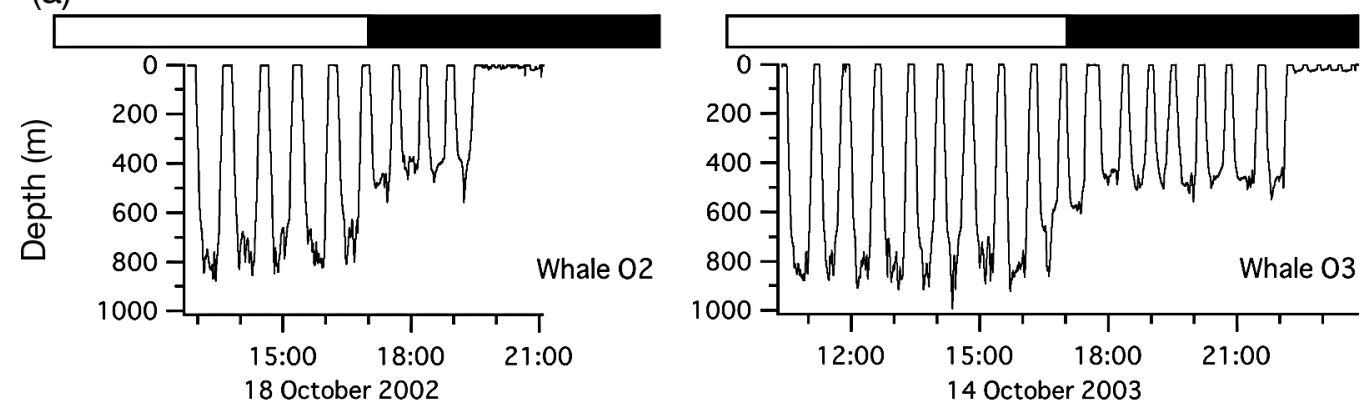

(b)
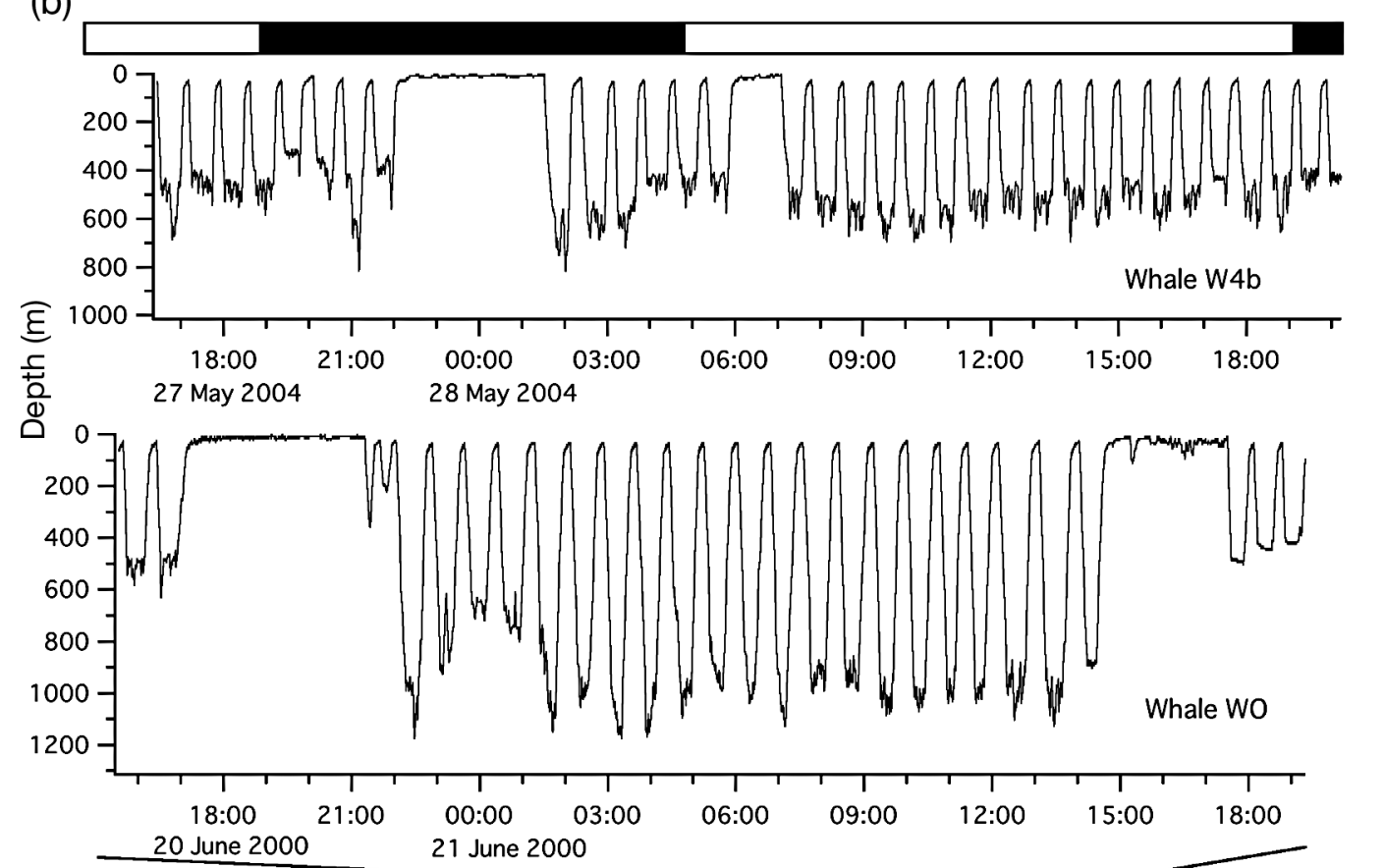

Fig. 2. Physeter macrocephalus. Typical dive depth profiles of 2 tagged sperm whales each (a) off the Ogasawara Islands and (b) off the Kumano Coast. Black and white bars indicate night and day, respectively

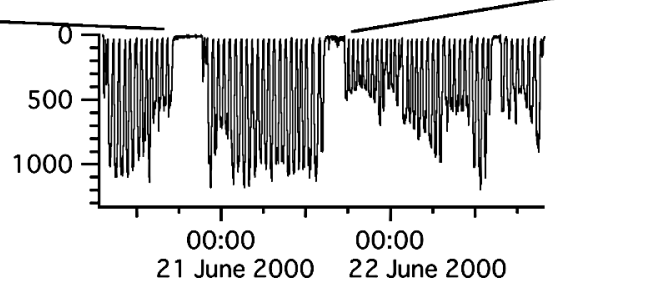


(a) Osagawara Islands

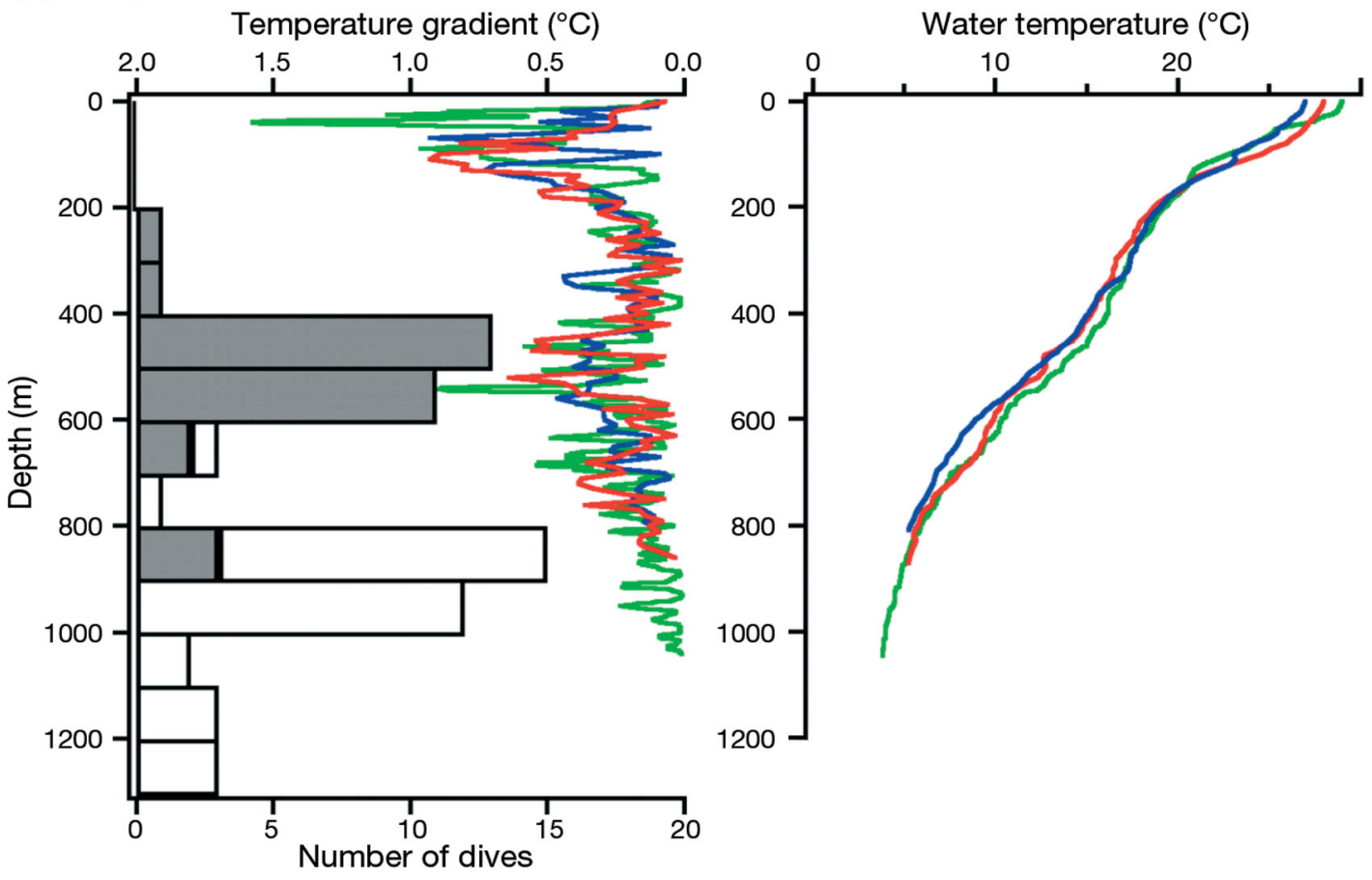

(b) Kumano Coast

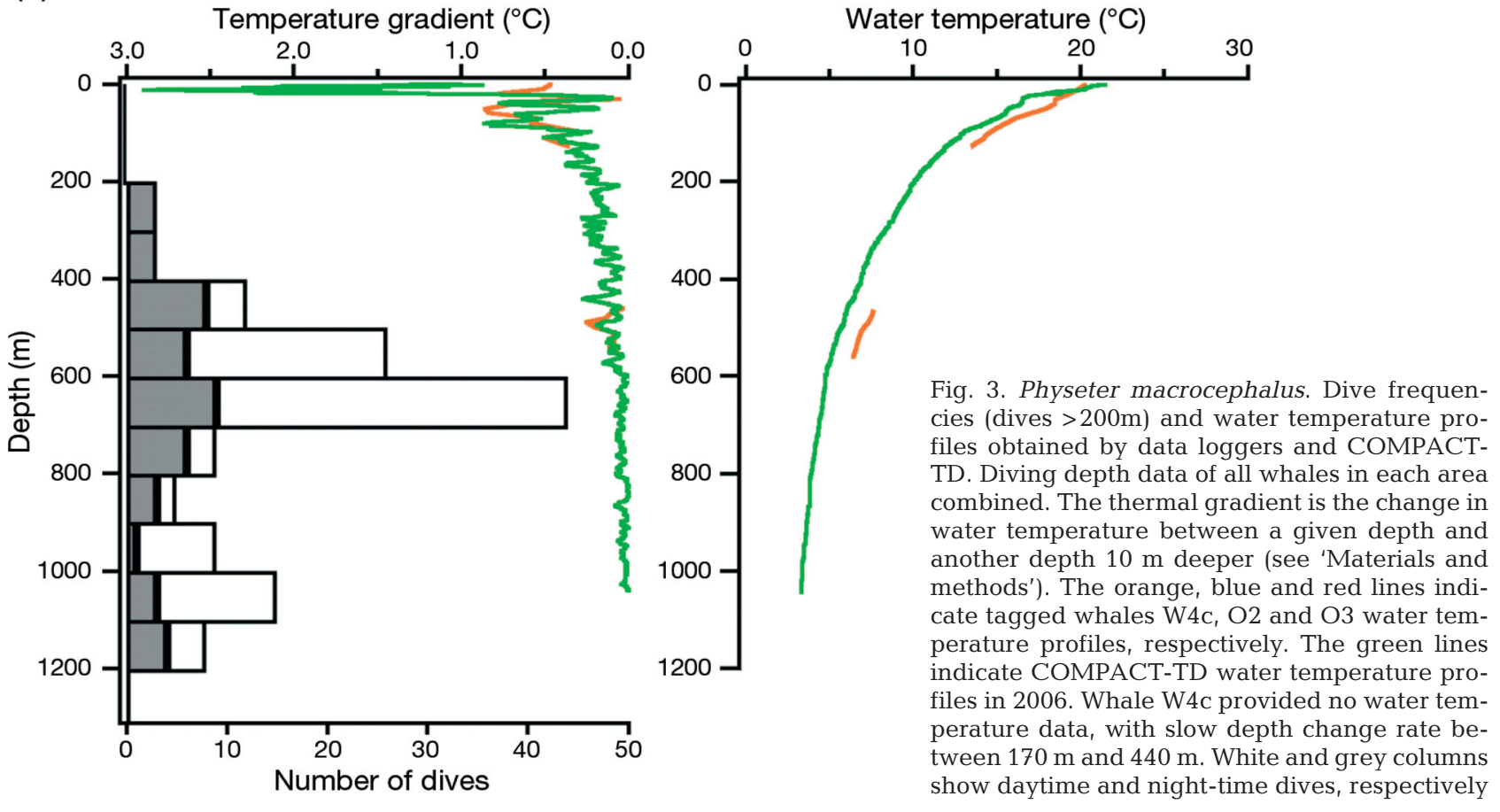

2 areas using repeated-measures ANOVA (Zar 1996). In a split-plot design, each dive record was assigned to either a 'day (local sunrise to sunset)' or 'night (local sunset to sunrise)' condition and each whale record was assigned to either the Ogasawara Islands or the Kumano Coast area. The model included both 'day/night' and 'area' as the fixed factors and 'whale' as the random factor. The mean-square interaction between 'day/ night' and 'area' was assessed with the F-ratio with a denominator that was the mean-square interaction of 'day/night', with 'whale' nested within its area. The interaction was significant $\left(F_{(2) 1,8}=13.2, \mathrm{p}<0.02\right)$. 
Since the area $\times$ day/night interaction was significant, we tested differences in dive parameters between day and night in each area separately using a 2-factor ANOVA with repeated measures (Table 2). Off the Ogasawara Islands, diving parameters were significantly different between day and night: mean dive depth was deeper, duration was longer, velocity in the bottom phases was faster, and number of wiggles in the bottom phases was larger during the day than night (Table 2, Appendix 1). On the other hand, off the Kumano coast, mean dive depth, dive duration, velocity and the number of wiggles in the bottom phases were not different between day and night (Table 2, Appendix 2).

\section{Diving behavior in relation to temperature profiles}

We plotted the frequency distribution of maximum depths from all whales and vertical profiles of water temperature obtained by data loggers and COMPACT-TD in each area (Fig. 3). The temperature profiles showed a rapid decline in the upper $200 \mathrm{~m}$ from the surface in both areas: from $27.0^{\circ}-29.0^{\circ} \mathrm{C}$ to $18.7^{\circ}-19.3^{\circ} \mathrm{C}$ off the Ogasawara Islands and from $20.3^{\circ}-21.5^{\circ} \mathrm{C}$ to $10.1^{\circ} \mathrm{C}$ off the Kumano Coast. The thermal gradient between the surface and $200 \mathrm{~m}$ was steep in both areas, which indicated a seasonal thermocline (Fig. 3). Below the $200 \mathrm{~m}$ depth, temperature decreased gradually with depth, and the thermal gra- dient was relatively weak (range 0 to 0.28 ) off the Kumano Coast (Fig. 3b). These temperature profiles indicated that there was no clear thermocline in the mesopelagic water. Sperm whales dived to various depths during both the day and night off the Kumano Coast (Fig. 3). On the other hand, off the Ogasawara Islands, the thermal gradient became steeper at approximately 350 to $550 \mathrm{~m}\left(0.44^{\circ} \mathrm{C}\right.$ at $330 \mathrm{~m}$, Whale $\mathrm{O} 2 ; 0.64^{\circ} \mathrm{C}$ at $520 \mathrm{~m}$, Whale $\mathrm{O} 3$; and 0.89 at $540 \mathrm{~m}$, COMPACT-TD), which indicated the presence of a thermocline in the mesopelagic water (Fig. 3a). The whales made deep dives beyond the thermocline during the day, but they dived to around the thermocline at night off the Ogasawara Islands (Fig. 3a). To examine whether the relationship between distribution of maximum depths and presence of the thermocline in mesopelagic water was different between day and night off the Ogasawara Islands, we performed the following analysis between 200 and $1100 \mathrm{~m}$. We defined the thermocline as a temperature gradient obtained by COMPACT-TD of more than $0.5^{\circ} \mathrm{C}$ and then examined the presence or absence of the thermocline $50 \mathrm{~m}$ above and below the maximum dive depth. We then compared the number of dives with and without the thermocline between day and night. Night dives with the thermocline were significantly higher in number than day dives (Fisher's exact test, 2-tailed, $\mathrm{p}<0.00001$ ).

Water temperature profiles obtained with the data loggers and COMPACT-TD off the Ogasawara Islands

Table 2. Physeter macrocephalus. Comparison of dive parameters of sperm whales between day and night for Ogasawara Islands and Kumano Coast, together with results of statistical analysis. ' $n$ ' is the total number of dives in each area. Dive parameters were compared between day and night in each area using 2-factor ANOVA with repeated-measures (See 'Materials and methods, Data analysis' for details). The statistical comparisons were 2-tailed, and values for statistical significance were set at $\mathrm{p}<0.05 .{ }^{*} \mathrm{p}<0.05,{ }^{* *} \mathrm{p}<0.01,{ }^{* * *} \mathrm{p}<0.001, \mathrm{NS}$ : not significant. See 'Materials and Methods' for definition of wiggles

\begin{tabular}{|c|c|c|c|c|c|c|c|}
\hline Parameter & $\begin{array}{c}\text { Day } \\
\text { Means } \pm \mathrm{SD}\end{array}$ & $\mathrm{n}$ & $\begin{array}{r}\text { Night } \\
\text { Means } \pm \text { SD }\end{array}$ & $\mathrm{n}$ & $\mathrm{df}$ & $F$ & $\mathrm{p}$ \\
\hline \multicolumn{8}{|l|}{ Ogasawara Islands } \\
\hline Mean dive depth (m) & $853 \pm 130$ & 35 & $469 \pm 122$ & 31 & 1.5 & 84.2 & $* * *$ \\
\hline Dive duration (min) & $40.1 \pm 4.5$ & 35 & $32.3 \pm 5.3$ & 31 & 1.5 & 16.8 & $* *$ \\
\hline Bottom time (min) & $20.7 \pm 3.6$ & 35 & $17.2 \pm 5.2$ & 31 & 1.5 & 5.8 & NS \\
\hline Descent rate $\left(\mathrm{ms}^{-1}\right)$ & $1.4 \pm 0.2$ & 35 & $0.9 \pm 0.2$ & 31 & 1.5 & 53.2 & $* *$ \\
\hline Ascent rate $\left(\mathrm{ms}^{-1)}\right.$ & $1.5 \pm 0.2$ & 35 & $1.1 \pm 0.3$ & 31 & 1.5 & 12.4 & * \\
\hline Velocity (ms ${ }^{-1}$ ) (bottom) & $2.0 \pm 0.3$ & 20 & $1.5 \pm 0.3$ & 19 & 1.3 & 18.5 & * \\
\hline Wiggles $\left(\right.$ dive $\left.^{-1}\right)$ & $4.3 \pm 1.9$ & 35 & $2.2 \pm 1.8$ & 31 & 1.5 & 11.2 & * \\
\hline \multicolumn{8}{|l|}{ Kumano Coast } \\
\hline Mean dive depth (m) & $646 \pm 212$ & 83 & $561 \pm 229$ & 44 & 1.3 & 11.6 & NS \\
\hline Dive duration (min) & $36.1 \pm 3.7$ & 83 & $34.1 \pm 7$ & 44 & 1.3 & 0.8 & NS \\
\hline Bottom time (min) & $19.3 \pm 5.2$ & 83 & $17.5 \pm 6.6$ & 44 & 1.3 & 0.006 & NS \\
\hline Descent rate $\left(\mathrm{ms}^{-1}\right)$ & $1.3 \pm 0.2$ & 83 & $1.1 \pm 0.2$ & 44 & 1.3 & 6.2 & NS \\
\hline Ascent rate $\left(\mathrm{ms}^{-1}\right)$ & $1.3 \pm 0.2$ & 83 & $1.2 \pm 0.4$ & 44 & 1.3 & 5.2 & NS \\
\hline Velocity $\left(\mathrm{ms}^{-1}\right)$ (bottom) & $1.9 \pm 0.5$ & 57 & $1.6 \pm 0.5$ & 33 & 1.2 & 10.6 & NS \\
\hline Wiggles $\left(\right.$ dive $\left.^{-1}\right)$ & $4.3 \pm 2.2$ & 83 & $3.6 \pm 1.9$ & 44 & 1.3 & 1.0 & NS \\
\hline
\end{tabular}


were not significantly different (Mann-Whitney $U$-test: Whale O2, $\mathrm{p}=0.6452$; Whale O3, $\mathrm{p}=0.8384$ ).

\section{DISCUSSION}

\section{Diel diving behavior in both areas}

The tagged sperm whales spent most of their time in deep dives of $>200 \mathrm{~m}$ off both the Kumano Coast and the Ogasawara Islands. Almost all of the deep dives had a distinct bottom phase during which the depth varied widely, both during day and night. Similar deep dives in sperm whales were documented previously and interpreted as foraging dives (Watkins et al. 2002, Miller et al. 2004b). Furthermore, some bursts in velocity during the bottom phases were observed, which suggests predation events (Amano \& Yoshioka 2003). Thus, we think that the whales must forage regardless of day or night in both areas.

We found obvious diel patterns of diving behavior off the Ogasawara Islands, where sperm whales dived to 800-1000 $\mathrm{m}$ during the day, but the dive depth decreased just after sunset, and the whales dived to 400-600 m at night. Also, the velocity in the bottom phases was slower and the number of wiggles was smaller at night than day, which suggests that the whales were relatively inactive at night. Amano \& Yoshioka (2003) suggest that deep inactive dives, such as those observed for Whale W0, which had flat bottom phases in terms of depth and no bursts in velocity, indicate resting or food processing. Whale W0 had 4 deep inactive dives (Amano \& Yoshioka 2003). However, we think that the inactive dives observed off the Ogasawara Islands were different from those reported by Amano \& Yoshioka (2003) because these inactive dives had bursts in velocity during the bottom phases. On the other hand, off the Kumano Coast whales showed no diel rhythm in diving behavior. Similarly, none of the previous studies have shown obvious diel changes in diving depth of sperm whales in any area (Papastavrou et al. 1989, Watkins et al. 2002, Davis et al. 2007). This study is the first to detect obvious diel changes in the diving behavior of sperm whales.

Long surface times, during which the whales did not make deep dives, have been suggested to indicate socializing or resting (Amano \& Yoshioka 2003). These surface times were observed at night off the Ogasawara Islands and at various times off the Kumano Coast. These differences in feeding time may be related to food availability. Food supply may vary more off the Kumano Coast than off the Ogasawara Islands. We suggest that environmental differences between the 2 areas influenced the different diel behaviors of the whales.

\section{Factors possibly related to the diel behavior of sperm whales}

We consider that diel diving patterns of the whales are closely related to the behavior, distribution or species of their prey. Off the Ogasawara Islands, the velocity in the bottom phases was slower and the number of wiggles was smaller at night than during the day. We propose 2 hypotheses to explain the diel patterns in velocity and wiggles in the bottom phases. (1) Velocity and wiggles in the bottom phases depend on prey density. Some squids change density between day and night. For example, Gonatus onyx (Gonatidae) off southern California have been reported to disperse vertically between 400 and $800 \mathrm{~m}$ during the day and gathered between 300 and $500 \mathrm{~m}$ at night (Roper \& Young 1975). Perhaps the whales do not need to swim fast or move up and down as much when the prey density is high. (2) Velocity and the number of wiggles in the bottom phases depend on the species of prey. For example, Wilson et al. (2002) determined that penguins feeding on small swarming crustaceans tended to reduce their speed during prey exploitation, whereas those feeding on larger fish tended to increase their speed. The squids that sperm whales feed on vary in size from the small Histioteuthids $(<400 \mathrm{~g})$ to the Architeuthids, or giant squids (up to $400 \mathrm{~kg}$ ). They also vary in activity, from the active Ommastrephids to the placid gelatinous Histioteuthids (Whitehead 2003).

We consider that hypothesis (1) more likely applies to whales off the Ogasawara Islands. In other words, their diel diving patterns depend on the diel vertical migration patterns of their prey, the density of which changes between day and night. It has been reported that some whales change their diving depth between day and night, following diel vertical migrations of their prey (Leatherwood \& Evans 1979, Croll et al. 1988, Baird et al. 2001, 2002). For example, the dive depths of blue whales Balaenoptera musculus equipped with time-depth recorders off the California Channel Islands were correlated with the depths of the densest schools of euphausiids throughout the day, and the whales were shown to track the migration of krill towards the surface at sunset (Croll et al. 1988). For sperm whales in Japanese waters, squid from the families Histioteuthidae, Octopoteuthidae, Onychoteuthidae and Ommastrephidae are important prey (Kawakami 1980), and some of these undergo diel vertical migrations. For example, several species of Histioteuthids off the California and Bermuda coasts maintain deeper depths during the day (400 to $800 \mathrm{~m}$ ) than at night (upper $400 \mathrm{~m}$ ) (Roper \& Young 1975). Moroteuthis sp. (Onychoteuthidae) in the Antarctic Ocean maintain depths of 735 to $950 \mathrm{~m}$ during the day and 
388 to $791 \mathrm{~m}$ at night (Moiseev 1991). Thus, some of these squid probably make diel vertical migrations off Japan, affecting the foraging depth of sperm whales. Furthermore, whales dived to around the thermocline at night off the Ogasawara Islands, where a thick thermostad (NPSTMW), with temperatures ranging from 15 to $19^{\circ} \mathrm{C}$, sits at a depth of 150 to $400 \mathrm{~m}$ almost all year (Taneda et al. 2000). We consider that the thermocline we observed corresponds to the margin of NPSTMW. It has been suggested that thermoclines are important because changes in water density allow organic material to sink from above (Lalli \& Parsons 1993). For this reason, the dive depth is closely correlated with vertical temperature profiles for some diving animals. For example, king penguins and southern elephant seals have been observed diving frequently to the thermocline, which is likely to concentrate their prey (Boyd \& Arnbom 1991, Charrassin \& Bost 2001). Therefore, off the Ogasawara Islands, we assume that the margin enhances biological activity and concentrates mesopelagic squid and fish, which conduct diel vertical migrations. In addition - on the basis of information obtained from studies using midwater trawls off the Ogasawara Islands - the biomass of some mesopelagic organisms was abundant at 800 to $1000 \mathrm{~m}$ during the day, and this rich layer of organisms rose up to a shallower depth of $350 \mathrm{~m}$ at night (K. Mori pers. comm.). These organisms should include large squids, i.e prey of sperm whales.

We have no idea why the long surface times during which whales did not dive were observed at night off the Ogasawara Islands. Generally, if prey conduct diel vertical migration, nocturnal feeding requires lower commuting cost than does diurnal feeding for the whales because their prey remains in relatively shallow waters at night (Kooyman et al. 1992); hence, many smaller toothed whales prefer to feed at night (e.g. Leatherwood \& Evans 1979). Therefore, before our experiments were conducted, we expected long surface times to occur at any time other than during the night because surface time should minimize disruption of foraging. However, our results off the Ogasawara islands did not coincide with the case described above. The case of the sperm whales did not correspond with that of the smaller toothed and baleen whales. Whitehead \& Weilgart (1991) also reported that a long surfacing time in the afternoon did not correspond to a reduction in successful feeding at this time of the day off the Galapagos Islands. There may be a trade-off between foraging and the risk of predation. Alternatively, periods of long surfacing time may depend on other factors, such as socializing.

Off the Kumano Coast, whales showed no diel diving patterns, which we believe is due to a lack of diel vertical migration among their prey. In other words, their prey may be different from that of whales off the Ogasawara Islands. Alternatively, prey may disperse vertically because there was no clear thermocline in the mesopelagic water. Our results also support the idea that the diving depth of these whales is closely related to oceanographic features.

In conclusion, diel behavior of sperm whales differed in terms of both diving behavior and feeding time zone off the Kumano Coast and off the Ogasawara Islands. Environmental differences between these two areas may have contributed to the different diel behaviors of the whales, which were mediated by the diel distribution patterns and availability of their prey. Some studies indicate that a horizontal distribution of sperm whales is associated with physical and biological features (Jaquet \& Whitehead 1996, Griffin 1999), but it is not known how oceanographic features affect the use of vertical habitat by sperm whales. Our results suggest that the dive depth of whales is closely related to the water temperature structure. We have to continue to research the relationships among behavior of the whales, their prey and oceanographic features in order to understand their interaction.

Acknowledgements: We thank Nanki Marine Leisure Service and S. Yokoyama, who provided their boat for the research; F. Nakahara, T. Kaneko, T. Hasegawa; the staff of SEA TAC and the Ogasawara Whale Watching Association; and the many volunteers who helped with the fieldwork. A. Hayano determined the sex of the tagged whales. Members of the International Coastal Research Center, the Ocean Research Institute, the University of Tokyo, the OKAMOTO shipyard, and Little Leonardo helped with the tag design. A. Takahashi, K. Sato, M. Oka, T. Johnson, T. Kitagawa, Y. Naito, Y. Watanabe, and P. J. O. Miller provided us with many helpful suggestions. This study was supported by the Sasakawa Scientific Research Grant from the Japan Science Society and Grant-inAids from the Ministry of Education, Culture, Sports, Science and Technology, Japan (12NP0201 and 15570012).

\section{LITERATURE CITED}

Amano M, Yoshioka M (2003) Sperm whale diving behavior monitored using a suction-cup-attached TDR tag. Mar Ecol Prog Ser 258:291-295

Baird RW, Ligon AD, Hooker SK, Gorgone AM (2001) Subsurface and nighttime behaviour of pantropical spotted dolphins in Hawai'i. Can J Zool 79:988-996

Baird RW, Borsani JF, Hanson MB, Tyack PL (2002) Diving and night-time behavior of long-finned pilot whales in the Ligurian Sea. Mar Ecol Prog Ser 237:301-305

Blackwell SB, Haverl CA, Le Boeuf BJ, Costa DP (1999) A method for calibrating swim-speed recorders. Mar Mamm Sci 15:894-905

Boyd IL, Arnbom T (1991) Diving behaviour in relation to water temperature in the southern elephant seal: foraging implications. Polar Biol 11:259-266

Charrassin JB, Bost CA (2001) Utilisation of the oceanic habitat by king penguins over the annual cycle. Mar Ecol Prog Ser 221:285-297

Charrassin JB, Park YH, Maho YL, Bost CA (2004) Fine reso- 
lution 3D temperature fields off Kerguelen from instrumented penguins. Deep-Sea Res I 51:2091-2103

Croll DA, Tershy BR, Hewitt RP, Demer DA and 8 others (1988) An integrated approach to the foraging ecology of marine birds and mammals. Deep-Sea Res II 45: 1353-1371

Davis RW, Jaquet N, Gendron D, Markaida U, Bazzino G, Gilly W (2007) Diving behavior of sperm whales in relation to behavior of a major prey species, the jumbo squid, in the Gulf of California, Mexico. Mar Ecol Prog Ser 333: 291-302

Griffin RB (1999) Sperm whale distributions and community ecology associated with a warm-core ring off Georges Bank. Mar Mamm Sci 15:33-51

Jaquet N, Whitehead H (1996) Scale-dependent correlation of sperm whale distribution with environmental features and productivity in the South Pacific. Mar Ecol Prog Ser 135: $1-9$

Kasuya T, Ohsumi S (1966) A secondary sexual character of the sperm whale. Sci Rep Whales Res Inst 20:89-93

Kawakami T (1980) A review of sperm whale food. Sci Rep Whales Res Inst 32:199-218

Kooyman GL, Cherel Y, Maho YL, Croxall JP, Thorson PH, Ridoux V, Kooyman CA (1992) Diving behavior and energetics during foraging cycles in king penguins. Ecol Monogr 62:143-163

Lalli CM, Parsons TR (1991) Biological Oceanography: an Introduction. Pergamon Press, Oxford

Leatherwood S, Evans WE (1979) Some recent uses and potentials of radiotelemetry in field studies of cetaceans. In: Winn HE, Olla BL (eds) Behavior of Marine Animals, current perspectives in research, Vol 3. Cetaceans. Plenum Press, New York-London, p 1-31

Matsushita T (1955) Daily rhythmic activity of the sperm whale in the Antarctic Ocean. Bull Jpn Soc Sci Fish 20: 770-773

Miller PJO, Johnson MP, Tyack PL, Terray EA (2004a) Swimming gaits, passive drag, and buoyancy of diving sperm whales (Physeter macrocephalus). J Exp Biol 207: 1953-1967

Miller PJO, Johnson MP, Tyack PL (2004b) Sperm whale behaviour indicates the use of echolocation click buzzes 'creaks' in prey capture. Proc R Soc Lond SerB Biol Sci 271:2239-2247

Moiseev SI (1991) Observation of the vertical distribution and behavior of nektonic squids using manned submersibles. Bull Mar Sci 49:446-456

Mori K, Sato F, Yamaguchi M, Suganuma H (1995) Preliminary report of distribution, movement and school structure of the sperm whale in the adjacent waters of the Ogasawara (Bonin) Islands. Abstracts of Eleventh Biennial Conference on the Biology of Marine Mammals, Orlando, FL, p 80

Panigada S, Zanardelli M, Canese S, Jahoda M (1999) How deep can baleen whales dive? Mar Ecol Prog Ser 187: 309-311

Papastavrou V, Smith SC, Whitehead H (1989) Diving behaviour of the sperm whale, Physeter macrocephalus, off the Galapagos Islands. Can J Zool 67:839-846

Roper CFE, Young RE (1975) Vertical distribution of pelagic cephalopods. Smithson Contrib Zool 209:1-51

Takahashi I (2001) Relationship between occurrence of sperm whale and oceanographic conditions in Kumano Sea, Japan. MS thesis, Mie University, Tsu

Taneda T, Suga T, Hanawa K (2000) Subtropical mode water variation in the northwestern part of the North Pacific subtropical gyre. J Geophys Res 105:19591- 19598

Watkins WA, Daher MA, DiMarzio NA, Samuels A, Wartzok D, Fristrup KM, Howey PW, Maiefski RR (2002) Sperm whale dives tracked by radio tag telemetry. Mar Mamm Sci 18:55-68

Watwood SL, Miller PJO, Johnson M, Madsen PT, Tyack PL (2006) Deep-diving foraging behaviour of sperm whales (Physeter macrocephalus). J Anim Ecol 75:814-825

Whitehead H (2003) Sperm whales: social evolution in the ocean. The University of Chicago Press, Chicago, IL

Whitehead H, Weilgart L (1991) Patterns of visually observable behavior and vocalizations in groups of female sperm whales. Behav 118:275-296

Wilson R, Ropert-Coudert Y, Kato A (2002) Rush and grab strategies in foraging marine endotherms: the case for haste in penguins. Anim Behav 63:85-95

Zar JH (1996) Biostatistical analysis, 3rd edn. Prentice-Hall, Englewood Cliffs, NJ 
Appendix 1. Physeter macrocephalus. Comparison of dive parameters of sperm whales between day and night off Ogasawara Islands. Means \pm SD are shown for each individual. See 'Materials and methods' for definition of 'wiggles'

\begin{tabular}{|c|c|c|c|c|c|c|}
\hline \multirow{2}{*}{$\begin{array}{l}\text { Whale ID } \\
\text { Parameter }\end{array}$} & \multicolumn{2}{|c|}{ O1a } & \multicolumn{2}{|c|}{ O1b } & \multicolumn{2}{|c|}{$\mathrm{O} 1 \mathrm{c}$} \\
\hline & Day & Night & Day & Night & Day & Night \\
\hline $\mathrm{n}$ & 6 & 2 & 5 & 9 & 7 & 7 \\
\hline Mean dive depth (m) & $806 \pm 122$ & $308 \pm 72$ & $947 \pm 136$ & $530 \pm 200$ & $968 \pm 208$ & $400 \pm 61$ \\
\hline Dive duration (min) & $38.9 \pm 1.9$ & $22.0 \pm 7.3$ & $43.7 \pm 1.8$ & $33.4 \pm 5.8$ & $46.3 \pm 2.7$ & $36.4 \pm 3.3$ \\
\hline Bottom time (min) & $18.1 \pm 3.3$ & $6.9 \pm 2.9$ & $24.4 \pm 3.1$ & $16.8 \pm 4.8$ & $23.7 \pm 3.4$ & $21.3 \pm 3.1$ \\
\hline Descent rate $\left(\mathrm{m} \mathrm{s}^{-1}\right)$ & $1.3 \pm 0.2$ & $0.7 \pm 0.1$ & $1.5 \pm 0.2$ & $1.0 \pm 0.2$ & $1.4 \pm 0.2$ & $1.0 \pm 0.2$ \\
\hline Ascent rate $\left(\mathrm{m} \mathrm{s}^{-1}\right)$ & $1.3 \pm 0.3$ & $0.7 \pm 0$ & $1.7 \pm 0.2$ & $1.1 \pm 0.3$ & $1.3 \pm 0.1$ & $1.0 \pm 0.1$ \\
\hline Velocity ( $\mathrm{m} \mathrm{s}^{-1}$, bottom) & $1.8 \pm 0.3$ & $1.1 \pm 0$ & $2.1 \pm 0.2$ & $1.6 \pm 0.3$ & $2.1 \pm 0.1$ & $1.5 \pm 0.1$ \\
\hline \multirow[t]{2}{*}{ Wiggles $\left(\operatorname{dive}^{-1}\right)$} & $3.3 \pm 2.4$ & $0.5 \pm 0.7$ & $6 \pm 1.4$ & $1.8 \pm 1.8$ & $6.1 \pm 1.6$ & $2.6 \pm 1.3$ \\
\hline & \multicolumn{2}{|c|}{$\mathrm{O} 2$} & \multicolumn{2}{|c|}{ O3 } & \multicolumn{2}{|c|}{$\mathrm{O} 4$} \\
\hline $\mathrm{n}$ & 6 & 4 & 9 & 8 & 2 & 1 \\
\hline Mean dive depth (m) & $765 \pm 46$ & $430 \pm 34$ & $802 \pm 45$ & $479 \pm 37$ & $830 \pm 83$ & 456 \\
\hline Dive duration (min) & $38.3 \pm 2.6$ & $30.7 \pm 1.8$ & $35.9 \pm 2.5$ & $31.0 \pm 3.6$ & $36.8 \pm 0.7$ & 32 \\
\hline Bottom time (min) & $20.9 \pm 1.5$ & $18.6 \pm 2.5$ & $18.4 \pm 2.2$ & $16.1 \pm 5.2$ & $18.6 \pm 2.5$ & 15.6 \\
\hline Descent rate $\left(\mathrm{m} \mathrm{s}^{-1}\right)$ & $1.3 \pm 0.2$ & $1.1 \pm 0.2$ & $1.5 \pm 0.2$ & $1.0 \pm 0.2$ & $1.4 \pm 0.1$ & 0.6 \\
\hline Ascent rate $\left(\mathrm{m} \mathrm{s}^{-1}\right)$ & $1.7 \pm 0.2$ & $1.2 \pm 0.3$ & $1.5 \pm 0.2$ & $1.3 \pm 0.4$ & $1.5 \pm 0.1$ & 1.6 \\
\hline Velocity ( $\mathrm{m} \mathrm{s}^{-1}$, bottom) & - \pm- & - \pm- & - \pm- & - \pm- & $2.1 \pm 0.3$ & 0.7 \\
\hline Wiggles $\left(\operatorname{dive}^{-1}\right)$ & $4.0 \pm 1.0$ & $2.3 \pm 1.5$ & $2.9 \pm 1.1$ & $1.6 \pm 1.1$ & $4.0 \pm 4.0$ & 5 \\
\hline
\end{tabular}

Appendix 2. Physeter macrocephalus. Comparison of dive parameters of sperm whales between day and night off Kumano coast. Means \pm SD are shown for each individual. See 'Materials and Methods' for definition of wiggles.

\begin{tabular}{|c|c|c|c|c|c|c|c|c|}
\hline \multirow{2}{*}{$\begin{array}{l}\text { Whale ID } \\
\text { Parameter }\end{array}$} & \multicolumn{2}{|c|}{ W0 } & \multicolumn{2}{|c|}{ W4a } & \multicolumn{2}{|c|}{ W4b } & \multicolumn{2}{|c|}{ W4c } \\
\hline & Day & Night & Day & Night & Day & Night & Day & Night \\
\hline $\mathrm{n}$ & 44 & 28 & 10 & 4 & 26 & 11 & 3 & 1 \\
\hline Mean dive depth $(\mathrm{m})$ & $757 \pm 238$ & $624 \pm 250$ & $547 \pm 29$ & $443 \pm 208$ & $506 \pm 56$ & $461 \pm 107$ & $570 \pm 57$ & 375.0 \\
\hline Dive duration (min) & $37.3 \pm 4.1$ & $34.5 \pm 7.7$ & $34.2 \pm 2.2$ & $29.2 \pm 10.2$ & $36.8 \pm 0.7$ & $32.0 \pm 0.0$ & $28.7 \pm 3.2$ & 32.3 \\
\hline Bottom time (min) & $17.8 \pm 5.9$ & $15.8 \pm 7.0$ & $19.3 \pm 3.0$ & $16.4 \pm 7.3$ & $22.4 \pm 2.9$ & $21.7 \pm 1.9$ & $15.2 \pm 4.1$ & 23.5 \\
\hline Descent rate $\left(\mathrm{m} \mathrm{s}^{-1}\right)$ & $1.4 \pm 0.2$ & $1.1 \pm 0.3$ & $1.2 \pm 0.1$ & $1.1 \pm 0.2$ & $1.2 \pm 0.2$ & $1.1 \pm 0.3$ & $1.3 \pm 0.1$ & 1.1 \\
\hline Ascent rate $\left(\mathrm{m} \mathrm{s}^{-1}\right)$ & $1.2 \pm 0.2$ & $1.1 \pm 0.3$ & $1.4 \pm 0.2$ & $1.2 \pm 0.6$ & $1.5 \pm 0.2$ & $1.4 \pm 0.2$ & $1.5 \pm 0.9$ & 1.5 \\
\hline Velocity ( $\mathrm{m} \mathrm{s}^{-1}$, bottom) & $1.8 \pm 0.6$ & $1.5 \pm 0.5$ & $2.0 \pm 0.2$ & $1.9 \pm 0.4$ & $0.6^{\mathrm{a}} \pm 0.1^{\mathrm{a}}$ & $0.7^{\mathrm{a}} \pm 0.5^{\mathrm{a}}$ & $1.8 \pm 0.0$ & 1.5 \\
\hline Wiggles $\left(\operatorname{dive}^{-1}\right)$ & $3.7 \pm 2.6$ & $3.0 \pm 1.8$ & $5.0 \pm 1.2$ & $4.3 \pm 2.5$ & $5.0 \pm 1.7$ & $4.9 \pm 1.4$ & $5.0 \pm 1.7$ & 5.0 \\
\hline
\end{tabular}

Editorial responsibility: Rory Wilson (Contributing Editor), Swansea, UK
Submitted: September 1, 2006; Accepted: May 23, 2007 Proofs received from author(s): October 22, 2007 